\title{
Effectiveness of Psychoeducation on Improving Opinions About Mental Illness Among Primary School Teacher Trainees in Kenya
}

\author{
Eunice Jemalel Nyavanga ${ }^{1,2, *}$, Ivy Mmbone Chebet ${ }^{3,4}$, Mourice Barasa ${ }^{5}$, David M. Ndetei ${ }^{6,7}$ \\ ${ }^{1}$ Department of Social and Human, Faculty of Social Sciences and Technology, The Technical University of Kenya, Nairobi, Kenya \\ ${ }^{2}$ Director of Malel Bibwob Clinical Psychologists Consultancy Ltd. (MICAP), Nairobi, Kenya \\ ${ }^{3}$ Department of Nursing, Faculty of Health Sciences, The Australian Catholic University, Melbourne, Australia \\ ${ }^{4}$ Neuroscience Ward St., Nursing Department, Vincent Private Hospital, Melbourne, Australia \\ ${ }^{5}$ International Planned Parenthood Federation - Africa Region, Nairobi, Kenya \\ ${ }^{6}$ Department of Psychiatry, Faculty of Health Sciences, The University of Nairobi, Nairobi, Kenya \\ ${ }^{7}$ African Mental Health Foundation, Nairobi, Kenya
}

\section{Email address:}

enyavanga@yahoo.com (E. J. Nyavanga), ivymmbone@yahoo.com (I. M. Chebet), barazam@gmail.com (M. Barasa)

${ }^{*}$ Corresponding author

\section{To cite this article:}

Eunice Jemalel Nyavanga, Ivy Mmbone Chebet, Mourice Barasa, David M. Ndetei. Effectiveness of Psychoeducation on Improving Opinions About Mental Illness Among Primary School Teacher Trainees in Kenya. Science Journal of Public Health. Vol. 4, No. 6, 2016, pp. 422-429. doi: $10.11648 /$ j.sjph.20160406.11

Received: July 30, 2016; Accepted: August 9, 2016; Published: September 2, 2016

\begin{abstract}
Opinions about mental illness have been found to be negative among college students and the general population. Studies have indicated that improving literacy levels would improve opinions and lead to individuals to seek help and family to provide the needed support. This study aimed to determine the effectiveness of psycho-education on the opinions about mental illness among public primary teacher trainees in Kenya. Convenience sampling was used to identify four public teacher colleges out of the twenty. Self-administered demographic questionnaire and opinions about mental illness scale were presented to the participants to collect data in four evaluations for the experimental group and three for the control group. The ethical protocol was followed from getting authority to informed consent from the participants. Out of the 2925 questionnaires presented, 2775 were returned fully filled, a return rate of $94.34 \%$. Summative scores improved among the experimental group in the second, and third assessments, but this reduced to almost the original measure in the fourth assessment. This study found that psycho-education of mental illness is effective in improving negative opinions about mental illness among these participants and this study recommended mental health studies is included in the teachers' curriculum.
\end{abstract}

Keywords: Mental Illness, Opinions, Psychoeducation, Teachers, Trainees, Effectiveness

\section{Introduction}

Opinions about mental illness in most of Africa are largely influenced by traditional beliefs that include punishment from God, being possessed by evil spirits $[1,2]$ that are caused and can be treated by supernatural beings [2,3]. In addition, young people have been found to experience stigma, feel embarrassed and to have problems in identifying the symptoms of mental illnesses due to limited mental health literacy, [1]. Opinions of mental illness have made the provision of health care services difficult, as the population believes that mental illness is incurable, Desjarlais et al as cited by Gureje and Alem [4]. Stigmatizing attitudes and discrimination are further made worse by inaccurate information about mental illness.

Mental illnesses are common and increasing in Kenyan Health facilities, with about $42.3 \%-66.2 \%$ identified cases among those attending health facilities with mild to severe depression, [5]. These increasing mental illnesses coupled with an increase in non-communicable diseases of HIV/AIDs 
rapid spread, cancer, and substance abuse and complications related to poverty, unemployment, displacement, internal conflict is increasing mental illnesses, in Kenya, [6, 7]. These are further complicated by social and cultural factors that include family dysfunctions, [8] poor parenting skills, poor attachments, violence, early experimentation with drugs of abuse (including alcohol) and sex, Gallagher, et al as quoted by both Kitzrow and Benton at al, [9, 10].

Reavley and Jorm, [11] in as study of stigmatizing attitudes towards people with mental illness in Australia, further indicated that stigma has a great impact on service delivery and recovery from mental illness. This has led to challenges for service delivery capacity building in Kenya, [12].

At all levels of health service delivery in Kenya, there are shortages of mental health workers and in addition, these health workers have low levels of mental health literacy, [7]. Jorm [13] has defined mental health literacy as "that knowledge and beliefs about mental illness that aid their recognition, management, and prevention.

Justifications and Significance of Study

The mental health Global Action Programme was introduced by the World Health Organization (WHO) in 2002 and was intended to reduce the gap in accessing mental healthcare in low-income countries like Kenya, [14]. This programme recommended psychoeducation to improve opinions about mental illness. Despite this, no known study has been done to indicate whether psychoeducation could contribute to improved opinions about mental illness among the youth in Kenya. In a study of opinions about mental illness among college students in Kenya, Nyavanga and Barasa, [15] found negative opinions about mental illness and recommended an intervention in the form of psychoeducation in order to improve opinions about mental illness that would lead to improved attitudes to seeking professional psychological help for a mental illness.

Gulliver et al, [1] identified that some of the key barriers to professional psychological help seeking for a mental illness problem, include lack of knowledge on mental health services, public stigmatizing attitudes towards mental illness, and difficulty in identifying symptoms of mental illness. In addition, Gureje and Alem [4] proposed that mental health literacy should include positive improvement of perceptions of mental illness and promotion of research in mental illness in Africa because opinions about mental illness are more influenced by supernatural beliefs.

This study, therefore aims to determine whether psychoeducation on what mental illness is, causes, effects on individuals and others, signs and symptoms, common mental illness among college students, treatment and myths of mental illness could improve the negative opinions about mental illness and sustain that improvement for about six months.

\section{Methods}

\subsection{Settings and Study Population}

This study is part of a larger longitudinal quasi-experimental study, "The Effects of Psycho-education on Mental Health Consultation Attitudes among Primary School Teacher Trainees in Kenya".

Four out of twenty primary public teachers training colleges were conveniently sampled. These trainees were recruited to colleges in a quota system throughout the country. The Ministry of Education (Statistics Department) estimated that the effective population from this sampled colleges would be 3,400 out of a total of 17,000 in the twenty colleges. All trainees who consented from these sampled colleges were recruited for the study to increase the generalizability of the findings. A total of 2925 participants were recruited but only 2777 completed the study during the baseline evaluation, a response rate of $94.34 \%$.

\subsection{Ethical Consideration}

The Kenyatta National Hospital and Nairobi University Ethics Committee approved the study protocol. The Ministry of Education (Research Department) granted permission for this study. This approval and permission were presented to the college heads, with an explanation of the purpose, plan, and implication of the study, before requesting for a written informed consent and plan on how the study would be done in each college. The students were met in a college assembly and the purpose, plan, and implication of the study were explained. They were also told that taking part in the study was voluntary and with no intrusive procedures and if they felt emotional during data collection they would see the college counselor or the team of research assistants or the researchers, whose contacts were also provided.

\subsection{Instrumentations}

Researchers developed self-administered demographic questionnaire and Opinions about Mental Illness Scale (OMI) by Cohen and Struening, 1962, [16] was presented to the participants while sited in their classrooms. The demographic questionnaire asked the participants their year of study, age, gender, religion, marital status, whether they taught as untrained teachers before coming to college and whether they grew up in a rural or urban setting.

Cohen and Struening developed the OMI in 1962 and later modified by Struening and Cohen in 1965 . The scale consists of 51 items scored on a six-point Likert scale ranging from strongly disagree (score 1) to strongly agree (score 6). Through factor analysis, Cohen and Struening [17] discovered that each of these items contributes to five opinion dimensions. Two of these opinions reflect negative opinions; two reflect positive opinions while the fifth reflect treatability and causes of mental illness. High scores indicate a belief that is represented by the corresponding factor.

The five dimensions of OMI include (1) authoritarianism-the opinion that people with a mental illness cannot be held accountable for their acts and they should be controlled by society; (2) benevolence-an attitude that could be placed on tolerance and pity/compassion; (3) mental hygiene ideology-the opinion that mental illness is similar to other illnesses and it 
should be treated adequately by specialists; (4) social restrictiveness-the opinion that mentally ill persons should be restricted in some social domains; and (5) interpersonal etiology - the belief that the real cause of a mental illness are the problematic interpersonal relations which arise from deprivation of parental love during childhood.

\subsection{Study Procedures}

A team of six research assistants (psychologists with at least an undergraduate degree) was trained on the purpose, procedure, and implications of the study in a day of two sessions of two hours each. They also participated in trying the tools on a group of university diploma college students not included in the study. These research assistants assisted the researchers in both data collection and psycho-education.

In order to make sure that college counselors had basic counseling skills on counseling and referring participants who self-referred selves to the counselor, the researchers trained them in a session of two hours on basic counseling skills for a mental illness. The researchers met the officers in charge of guidance and counseling to discuss how they would go about counseling of self-referred participants in relation to issues that came up during the study. This was to make sure that all college counselors got basic skills on counseling and referring the participants appropriately.

The researchers, with the help of research assistants, explained the purpose, the procedure and the implications of this research for the participants in their normal classrooms. They were told that participation was voluntary and they could discontinue at any time without any victimization. The tools were presented in their classrooms of about 42 students each, and this took about forty-five (45) minutes to complete. They were assured of confidentiality and requested to indicate their admission numbers only because of the need to use them during analysis and this numbers would be coded by the principal researcher during data entry but not used to identify any individual participant. They were also told that results would be reported anonymously without any particular individual identified and those who would want to know their evaluation status could contact the principal researcher.

After reading and agreeing on the informed consent, participants completed the measures in the survey with the assistance of the research team, folded them, stapled them together and put them in a sealed ballot box that was placed in front of the class.

The experimental group was given a psycho-education using PowerPoint presentations in the college classrooms for about two hours and thirty minutes question and answer period while sited in groups of about 100 participants in each group. Both groups were all evaluated again a day after the psycho-education among the experimental group. The second evaluation added a question, which asked participants whether they had participated in the baseline data collection and psycho-education (for the experimental group only). The third evaluation using the same tools was done three months after the second evaluation to both groups while the fourth one was done ten months after the first evaluation only to the experimental group. During the fourth evaluation, psychoeducation, was also given to the control group, see Figure 1 below.

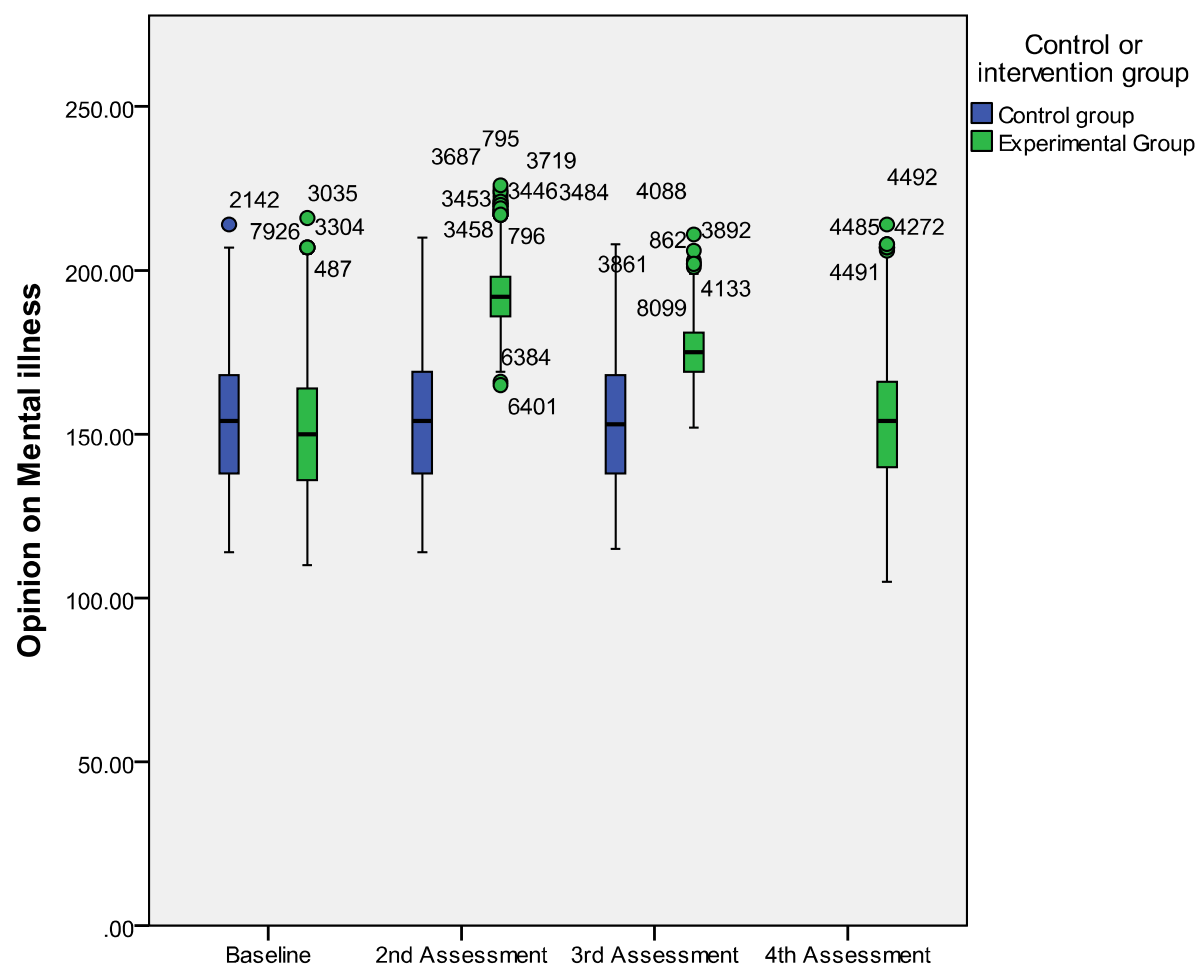

Trial number

Figure 1. Presentation of means summative scores of the comparison of OMI scale between both the experimental and control group through the four assessment trials. 


\subsection{Psychoeducational Training Module}

This module consisted of about 40 power point slides which indicated the meaning of mental health, mental illness, prevalence, comorbidity, causes, signs and symptoms, effects to the individual and others, risk factors, consequences at the school and the work place, treatments, and myths of mental illness.

\subsection{Data Analysis}

A one-way analysis of variance (ANOVA) F-test was used to determine whether there were any significant differences between the means of the control and experimental groups. In addition, a post-hoc (Fishers LSD) was also used to compare the baseline assessment with the other three consecutive assessments among the experimental group on the five dimensions of the OMI scale, after finding significant differences between the groups.

\section{Results}

\subsection{Summative Mean Scores of Both Groups in the Assessment Trials}

Observations in the second evaluation (soon after the psycho-education) among the experimental group indicate an increase (improvement) in summative scores of OMI as displayed in Diagram 1 above, as compared to the control group who did not receive the intervention. These scores among the experimental group reduce slightly in the third evaluation (done three months after baseline) and furthermore to almost the original during the fourth evaluation (10 months after the baseline). Observations from those of the control group remained almost constant throughout all the three evaluations, diagram 1 , above.

Table 1. Comparison of summative means scores (ANOVA) on opinion dimensions of OMI at the different evaluation trials among the control group.

\begin{tabular}{|c|c|c|c|c|c|c|}
\hline Opinion dimensions & Source of variation & Sum of Squares & df & Mean Square & $\mathbf{F}$ & Sig. \\
\hline \multirow{3}{*}{ A-Authoritarianism } & Between & 31.588 & 2 & 15.794 & \multirow{3}{*}{.682} & \multirow{3}{*}{.50} \\
\hline & Within & 84213.394 & 3636 & 23.161 & & \\
\hline & Total & 84244.983 & 3638 & & & \\
\hline \multirow{3}{*}{ B-Benevolence } & Between & 2.392 & 2 & 1.196 & \multirow{3}{*}{.032} & \multirow{3}{*}{.96} \\
\hline & Within & 136937.732 & 3636 & 37.662 & & \\
\hline & Total & 136940.124 & 3638 & & & \\
\hline \multirow{3}{*}{ C-Social Restrictiveness } & Between & 208.017 & 2 & 104.008 & \multirow{3}{*}{2.128} & \multirow{3}{*}{.115} \\
\hline & Within & 177734.610 & 3636 & 48.882 & & \\
\hline & Total & 177942.627 & 3638 & & & \\
\hline \multirow{3}{*}{ D-Mental Hygiene } & Between & 28.194 & 2 & 14.097 & \multirow{3}{*}{.785} & \multirow{3}{*}{.45} \\
\hline & Within & 65268.476 & 3636 & 17.951 & & \\
\hline & Total & 65296.670 & 3638 & & & \\
\hline \multirow{3}{*}{ E-Interpersonal Aetiology } & Between & 35.349 & 2 & 17.675 & \multirow{3}{*}{.492} & \multirow{3}{*}{.611} \\
\hline & Within & 130489.936 & 3636 & 35.888 & & \\
\hline & Total & 130525.285 & 3638 & & & \\
\hline
\end{tabular}

Table 2. Comparison of means (ANOVA) on opinion dimensions of OMI at the different evaluation trials among the experimental group.

\begin{tabular}{|c|c|c|c|c|c|c|}
\hline Opinion dimensions & Source of variation & Sum of Squares & df & Mean Square & $\mathbf{F}$ & Sig. \\
\hline \multirow{3}{*}{ A-Authoritarianism } & Between & 65286.306 & 3 & 21762.102 & \multirow{3}{*}{867.165} & \multirow{3}{*}{$.000 * *$} \\
\hline & Within & 136269.542 & 5430 & \multirow{2}{*}{25.096} & & \\
\hline & Total & 201555.849 & 5433 & & & \\
\hline \multirow[b]{2}{*}{ B-Benevolence } & Between & 174381.422 & 3 & 58127.141 & \multirow[b]{2}{*}{2204.074} & \multirow[b]{2}{*}{$.000 * *$} \\
\hline & Within & 143203.174 & 5430 & 26.373 & & \\
\hline \multirow{3}{*}{ C-Social restrictiveness } & Between & 35435.207 & 3 & 11811.736 & \multirow{3}{*}{454.558} & \multirow{3}{*}{$.000 * *$} \\
\hline & Within & 141098.970 & 5430 & \multirow{2}{*}{25.985} & & \\
\hline & Total & 176534.178 & 5433 & & & \\
\hline \multirow{3}{*}{ D-Mental Hygiene } & Between & 82763.785 & 3 & 27587.928 & \multirow{3}{*}{1824.455} & \multirow{3}{*}{$.000 * *$} \\
\hline & Within & 82108.067 & 5430 & \multirow{2}{*}{15.121} & & \\
\hline & Total & 164871.852 & 5433 & & & \\
\hline E-Interpersonal Aetiology & Between & 35218.358 & 3 & 11739.453 & 507.903 & $.000 * *$ \\
\hline
\end{tabular}




\subsection{Comparison of Summative Scores Using ANOVA at Different Assessment Trials}

\subsubsection{The Control Group}

OMI dimensions were analyzed using a one-way ANOVA (F-test) on opinions about mental illness among OMI factors in both groups. The control group did not show any significant variation in all the different evaluations $(p=0.05)$. This implies that there was no change in opinions about mental illness in this group, Table 2 above.

\subsubsection{The Experimental Group}

The experimental group showed significant variation between the first, the second and third evaluation. These results indicate a change in the means and trends in the experimental group, Table 2 above. Low scores on Factors A, $\mathrm{D}$, and $\mathrm{E}$ and high scores on Factors $\mathrm{B}$ and $\mathrm{C}$ indicate favorable opinions about mental illness.

\subsection{Post-Hoc Test (Fishers LSD) on the Five Dimensions of OMI Scale in the Experimental Group}

Post Hoc comparisons of the three assessment trials from the baseline assessment indicate that there was an improvement in all the OMI dimensions (factors) of OMI Scale.

Table 3. Post-Hoc test (Fisher's LSD) on the five dimensions of the OMI Scale among the Experimental group.

\begin{tabular}{|c|c|c|c|c|c|}
\hline Dependent Variable & (I) Trial number & (J) Trial number & Mean Difference (I-J) & Std. Error & Sig. \\
\hline \multirow{6}{*}{ Authoritarianism } & \multirow{3}{*}{ Baseline } & 2nd Assessment & $9.182 *$ & .186 & $.000 * *$ \\
\hline & & 3rd Assessment & $6.116^{*}$ & .191 & $.000 * *$ \\
\hline & & 4th Assessment & $3.654 *$ & .193 & $.000 * *$ \\
\hline & \multirow{2}{*}{ 2nd Assessment } & 3rd Assessment & $-3.066^{*}$ & .192 & $.000 * *$ \\
\hline & & 4th Assessment & $-5.528 *$ & .195 & $.000 * *$ \\
\hline & 3rd Assessment & 4th Assessment & $-2.462 *$ & .199 & $.000 * *$ \\
\hline \multirow{5}{*}{ Benevolence } & \multirow{2}{*}{ Baseline } & 2nd Assessment & $-12.960 *$ & .191 & $.000 * *$ \\
\hline & & 4th Assessment & .025 & .198 & .900 \\
\hline & \multirow{2}{*}{ 2nd Assessment } & 3rd Assessment & $4.346^{*}$ & .197 & $.000 * *$ \\
\hline & & 4th Assessment & $12.985^{*}$ & .200 & $.000 * *$ \\
\hline & \multirow[t]{2}{*}{ 3rd Assessment } & 4th Assessment & $8.640 *$ & .204 & $.000 * *$ \\
\hline \multirow{5}{*}{ Social restrictiveness } & & 2nd Assessment & $5.825^{*}$ & .189 & $.000 * *$ \\
\hline & \multirow{2}{*}{ Baseline } & 3rd Assessment & $3.621 *$ & .194 & $.000 * *$ \\
\hline & & 4th Assessment & -.187 & .196 & .341 \\
\hline & 2nd Assessment & 4th Assessment & $-6.012 *$ & .198 & $.000 * *$ \\
\hline & 3rd Assessment & 4th Assessment & $-3.808^{*}$ & .203 & $.000 * *$ \\
\hline \multirow{6}{*}{ Mental Hygiene } & \multirow{3}{*}{ Baseline } & 2nd Assessment & $-9.005^{*}$ & .144 & $.000 * *$ \\
\hline & & 3rd Assessment & $-.488 *$ & .148 & .001 \\
\hline & & 4th Assessment & .036 & .150 & .808 \\
\hline & \multirow{2}{*}{ 2nd Assessment } & 3rd Assessment & $8.517^{*}$ & .149 & $.000 * *$ \\
\hline & & 4th Assessment & $9.041 *$ & .151 & $.000 * *$ \\
\hline & 3rd Assessment & 4th Assessment & $.524 *$ & .155 & .001 \\
\hline \multirow{6}{*}{ Interpersonal Etiology } & \multirow{3}{*}{ Baseline } & 2nd Assessment & $4.802 *$ & .178 & $.000 * *$ \\
\hline & & 3rd Assessment & $5.375^{*}$ & .183 & $.000 * *$ \\
\hline & & 4th Assessment & -.002 & .185 & .991 \\
\hline & \multirow{2}{*}{ 2nd Assessment } & 3rd Assessment & $.573 *$ & .185 & .002 \\
\hline & & 4th Assessment & $-4.804 *$ & .187 & $.000 * *$ \\
\hline & 3rd Assessment & 4th Assessment & $-5.377 *$ & .191 & $.000 * *$ \\
\hline
\end{tabular}

Authoritarianism showed that the baseline means score was significantly higher than all the other trials ( $p$-value=0.000). A higher score in Authoritarianism implied a more unfavorable opinion implying an improvement immediately after psycho-education and the effect steadily reducing to almost the same level as the baseline as displayed by the reducing mean differences as seen in Table 3 above. Benevolence, social restrictiveness, mental hygiene and interpersonal etiology exhibited a significant improvement immediately after psych education and three months later (during 3rd assessment). In comparing the baseline to the 4th assessment there was no significant difference in the four factors, there was no significant difference, implying an equal mean at the two levels.

\section{Discussion, Conclusion, Recommendations and Limitations}

\subsection{Discussion}

\subsubsection{Summative OMI Score Improvement and Sustainability}

These two participant groups were similar in both demographic characteristics and baseline assessment, therefore, the change in the second, third and fourth evaluations were due to the psycho-education that was given.

Tests of significance in the effectiveness of psycho-education among participants indicated improvement only among the experimental group (who received the psycho-education). This study is consistent with other studies 
among the youth and college students globally, [18, 19, 20, 21, $22,23]$. This result implication suggests that for improvement in opinions of mental illness, psycho-education on meaning, causes, treatment and prognosis of mental illness is an approach necessary for any population to improve perceptions of mental illness. This improved perception is hoped to eventually improve the opinions about mental illness among teacher trainees, which is also further expected to lead to favorable attitudes towards professional psychological help seeking among participants for a mental health issue.

However, this improvement reduced with time from a day after, three months after and six months after the psycho-education respectively. This is consistent with other studies $[24,25,26]$ in a meta analysis, among various studies globally, where improvement was short-lived. Perron et al, [27] indicated a need for regular psycho-educational programs incorporated into the curriculum in colleges to increase the perceptions of mental illness among college students. Dalky [28] to sustain the perceptions of mental illness for a longer period, psychoeducation should use films, especially to the youth.

\subsubsection{OMI Dimensions Improvement and Sustainability \\ i. Authoritarianism}

Authoritarianism measures the opinion that people with mental illness cannot be held accountable for their acts and they should be controlled by society. With the intervention, this factor improved and was maintained throughout the six months. This means that with the short intervention, this group was able to change opinion that the mentally ill are not to blame for their illness.

\section{ii. Benevolence}

Benevolence factor measures attitude that could be placed on tolerance and pity/compassion. Significant improvement for this factor was only held to third evaluation, after three months, but this group came to almost the same mean at the fourth assessment ( 6 months after psychoeducation.

\section{iii. Social Restrictiveness}

Social Restrictiveness factor measured the opinions that mentally ill persons should be restricted in some social domains. Significant improvement for this factor was only held to the third assessment, that is three months after the intervention; this means that after three months their opinions were that the mentally ill should be restricted from other social domains. This is in line with other findings, [29].

\section{iv. Mental Hygiene}

Mental Hygiene ideology factor measures the opinions that the mentally ill persons have an illness like any other illnesses and should be treated by specialists. These participants were able to hold changed opinions up to the second assessments only, meaning that the idea that mental illness was like any other illness was not significantly held even at the third evaluation, three months after the intervention.

v. Interpersonal Etiology

Interpersonal Etiology factor measures the opinion that the real cause of a mental illness is the problematic interpersonal relations which arise from deprivation of parental love during childhood. These participants held these opinions significantly only to the third assessment, three months after the intervention, and were not able to reach the fourth evaluation, six months after the intervention

\subsection{Conclusion}

Opinions about mental illness improve with psychoeducation but are not sustained to over 10 months. Psycho-education improves all dimensions of opinions about mental illness, although it is not sustainable for more than ten months.

While the results of this study provides important information to the public health and the mental health sectors, that psychoeducation improves opinions about mental illness positively, that is not sustainable up to 10 months after the intervention. We cannot also therefore conclude this definitely because we need more research on a longer psychoeducatioon model that is spread for a few weeks to make a definite conclusion, However, this intervention can be used in a curriculum model where mental health education is given throughout the primary school teacher trainees so they can be able to may be sustain change longer. There is need to equip teacher trainees with mental health education so that they can identify, and refer students for appropriate treatments especially those who are involved in student guidance and counseling. This will go along way in the helping these students with mental health problems to seek help early enough to prevent adult mental health problems.

\subsection{Recommendations}

This study recommends that the Ministry of Education should incorporate mental health training in teacher training colleges to improve their opinions about mental illness. Positive opinions are expected to go a long way in helping these teachers in schools not only to identify and refer their students and themselves for treatment appropriately but to be able to understand their students, parents, and workmates and support while referring them for appropriate treatment.

\subsection{Limitations}

This study had limitations; (1) The OMI scale was self-reporting in nature, and could have had reporting bias, (2) although psychoeducation lectures were given in groups of between 90 to 100 students using powerpoint, we cannot guarantee that all the participants followed the lecture fully, (3) this psychoeducation was only a brief one, may be there would be need to have a longer session or more sessions to be able to make sure that the participants improved opinions for a longer time.

\section{Acknowledgements}

We would wish to acknowledge the African Mental Health Foundation (AMHF) and Bibwob-Malel Clinical Psychologists Consultants Ltd (MICAP), for the generous contribution they gave in terms of accessing the Internet, Journals, and Books used in this research. We also acknowledge Dr. Muthoni Mathai (who supervised principal 
researcher in the Dissertation) and Dr. Khasakhala (who assisted in the formative development in this study). In addition, we acknowledge the public primary college administration for allowing us to do this study and the student community for taking time to take part in the study in between very busy college schedules. This research was not funded.

\section{References}

[1] Gulliver, A., Griffins, K. M., \& Christensen, H. (2010) Perceived Barriers and Facilitators to mental Health Help-Seeking in Young People: A systematic Review. BMC Psychiatry; 10(113): 1-9. DOI: 10.1186/1471-244X-10-113.

[2] Makanjuola, J. D. A. and Oyerogba, K. O. (1987), Management of depressive illness in a Nigerian neuro-psychiatric hospital. Acta Psychiatrica Scandinavica, 76: 486-489. doi: 10.1111/j.1600-0447.1987.tb02908.x.

[3] Mbwayo, A. W., Ndetei, D. M., Mutiso, V. Khasakhala, L. I. (2013). Traditional healers and provision of mental health services in cosmopolitan informal settlements in Nairobi, Kenya. African Journal of Psychiatry, 16(2): http://dx.doi.org/10.4314/ajpsy.v16i2.17.

[4] Gureje, O. and Alem, A. (2000). Mental Health Policy Development in Africa. Bulletin of World Health Organization, 78 (4): 475-482.

[5] Ndetei, D. M., Khasakhala, L. I., Kuria, M. W., Mutiso, V. N., Ongecha-Owuor, F. A., and Kokonya, D. A. (2009). The prevalence of mental disorders in adults in different level general medical facilities in Kenya: a cross-sectional study. Ann Gen Psychiatry; 8: 1-8. Doi: 10.1186/1744-859X-8-1.

[6] Kiima, D., Jenkins, R. (2010). Mental Health Policy in Kenya An Integrated approach to scaling equitable care for poor Populations; International Journal of Mental Health Systems; 4 (19): doi: $10.1186 / 1752-4458-4-19$.

[7] Ndetei, D. M., Ongetcha, F. A., Mutiso, V., Kuria, M., Khasakhala, L. A., \& Kokonya, D. A. (2007). The challenges of human resources in mental health in Kenya. African Journal of Psychiatry, 10 (1), 33-36.

[8] Khasakhala, L. I., Ndetei, D. M., Mathai, M., and Harder, V., (2013). Major depressive disorder in a Kenyan youth sample: relationship with parenting behavior and parental psychiatric disorders. Annals of General Psychiatry: 12 (15): 1-13. DOI: 10.1186/1744-859X-12-15.

[9] Kitzrow, M. A. (2003). The Mental Health Needs of Today's College Student's: Challeges and Recommendations. NASPA Journal; 41 (1): 165-179.

[10] Benton, S. A., Benton, S. L., Newton, F. B., Benton, K. L., and Robertson, J. M. (2004). Changes in Client Problems: Contributions and Limitations From a 13-Year Study. Professional Psychology: Research and Practice, 35 (3): 317-319. http://dx.doi.org/10.1037/0735-7028.35.3.317.

[11] Reavley, N. J., Jorm, A. F. (2012). Stigmatizing attitudes towards people with mental disorders: Changes in Australia over 8 years. Psychiatry Research; 197 (3): 302-306. doi: 10.1016/j.psychres.2012.01.011.

[12] Muga, F. A., \& Jenkins, R. (2008). Public perceptions, explanatory models and service utilisation regarding mental illness and mental health care in Kenya. Social Psychiatry and Psychiatric Epidemiology, 43(6), 469 - 476. 10.1007/s00127-008-0334-0.

[13] Jorm, A. F. (2000). Mental Health Literacy: Public Knowledge and beliefs about Mental disorders. British Journal of Psychiatry; 177: 396-401.

[14] World Health Organization, (WHO). (2002). Mental Health Global Programme, (mhGAP).

[15] Nyavanga, E. J. \& Barasa, M. (2016). Opinions About Mental Illness Among Primary School Teacher Trainees in Kenya. Psychology and Behavioral Sciences; 5(3): 62-68. doi: 10.11648/j.pbs.20160503.11.

[16] Cohen, J. and Struening, E. L. (1962). Opinions about Mental Illness in the personnel of two large mental hospitals. Journal of Abnormal social Psychology; 64: 339-360.

[17] Cohen, J. and Struening, E. L. (1965). Simple-minded questions and twirling stools. Journal of Consulting $\begin{array}{lrll}\text { Psychology; } & 29 & \text { (3): }\end{array}$ http://dx.doi.org/10.1037/h0022131

[18] Sharp, W., Hangrove, D. S., Johnson, L., and Deal, W. P. (2006). Mental Health Education: An Evaluation of a Classroom Based Strategy to Modify Help Seeking for Mental Health Problems. Journal of College Student Development; 47 (4): 419-438. Doi: 10.1353/csd.2006.0051.

[19] Uta Gühne, Stefan Weinmann, Katrin Arnold, Thomas Becker, Steffi G. Riedel-Heller. (2015). S3 guideline on psychosocial therapies in severe mental illness: evidence and recommendations. European Archives of Psychiatry and Clinical Neuroscience; 265 (3): 173-188.

[20] Joanne Reid, Chris Lloyd, \& Lyn de Groot. (2005). The psychoeducation needs of parents who have an adult son or daughter with a mental illness, Australian e-Journal for Advancement of Mental Health; 4 (2): 65-77. Doi: 10.5172/jamh.4.2.65.

[21] Jorm, A. F., Medway, J., Christensen, H., Korten, A. E., Jacomb, P. A., \& Rodgers, B. (2000). Public beliefs about the helpfulness of interventions for depression: effects on actions taken when experiencing anxiety and depression symptoms. Australian and New Zealand Journal of Psychiatry; 34 (4): 619-626. Doi: 10.1080/j.1440-1614.2000.00761.x

[22] Tomaras, V. D., Ginieri-Coccossis, M., Vassiliadou, M., Malliori, M., Ferentinos, S., Soldatos, C. R., \& Tylee, A. (2011). Education in mental health promotion and its impact on the participants' attitudes and perceived mental health. Annals of general psychiatry, 10 (1), 1. DOI: 10.1186/1744-859X-10-33

[23] Watson, A. C., Oley, E., Westbrook, A. L., Gardener, A. L., Lamb, T. A., Corrigan, P. W. \& Fenton, W. S. (2004). Changing Middle Schoolers' Attitudes About Mental Illness Through Education. Schizophrenia Bulletin; 30 (3): 563-572.

[24] Corrigan, P. W., Morris, S. B., Michaels, P. J., Rafacz, J. D., \& Rüsch, N. (2012). Challenging the public stigma of mental illness: a meta-analysis of outcome studies. Psychiatric Services; 63: 963-973. Doi: 10.1176/appi.ps.005292011.

[25] Griffiths, K. M., Carron-Arthur, B., Parsons, A. \& Reid, R. (2012). Effectiveness of programs for reducing the stigma associated with mental disorders. A meta-analysis of randomized controlled trials. World Psychiatry; 13 (2): 161-175. DOI: 10.1002/wps.20129. 
[26] Papish, A., Kassam, A., Modgill, G., Vaz, G., Zanussi, L., \& Patten, S. (2013). Reducing the Stigma of Mental illness in undergraduate medical education: a randomized controlled trial. BMC Medical Education: 13: 141. Doi: 101186/1472-6920-13-141.

[27] Perron, B. E. Grahovac, I. D., Uppal, J. S., Granillo, T. M., Shutter, J., \& Porter, C. A. (2011). Supporting Students in Recovery on College Campuses: Opportunities for Student Affairs Professionals. Journal of Student Affairs Research and Practice: 48 (1): 47-64. DOI: 10.2202/1949-6605.6226.
[28] Dalky, H. F. (2012). Mental Illness Stigma Reduction Interventions: Review of Intervention Trials. Western Journal of Nursing research: 34 (4): 520-547. doi: $10.1177 / 0193945911400638$.

[29] Gonzalez, J. M., Tinsley, H. E. A. \& Kreuder, K. R. (2002) Effects of psychoeducational interventions on opinions of mental illness, attitudes toward help seeking, and expectations about psychotherapy in college students. Journal of College Student Development 43 (1): 51-63. 